\title{
Optimization of Antioxidant Extraction in Hylocereus Polyrhizus Seed using Response Surface Methodology
}

\author{
Siti Atikah Zulkifli, Siti Salwa Abd Gani, Uswatun Hasanah Zaidan, Mohd Izuan Effendi Halmi
}

\begin{abstract}
Seeds of red pitaya fruit (Hylocereus polyrhizus) are commonly left underutilized in the food industry. Thus, the objective of this present study was to optimize the extraction condition for the maximum DPPH radical scavenging activity of red pitay a fruit seed extract using response surface methodology (RSM). A Central Composite design was employed to determine the effects of the selected variables, comprising extraction time (30-90 min), extraction temperature $\left(40-80{ }^{\circ} \mathrm{C}\right)$ and ethanol concentration (60-80\%) on the DPPH scavenging activities. Data were analyzed by using Design Expert (version 10.0.1, Stat-Ease, Inc., Minneapolis, MN, USA) statistical analysis software. The optimal extraction conditions for the highest antioxidant capacity were derived at 45 mins of extraction time, $70^{\circ} \mathrm{C}$ extraction temperature and $80 \%$ ethanol concentration that resulted in $92.89 \%$ of scavenging activity. The optimized model developed was verified by comparing the predicted and experimental value of response. The result of measured response agreed well with the predicted values, demonstrating that the model can be used for optimizing the conditions of RSP extract that ensure high recovery of DPPH radical scavenging activity.
\end{abstract}

Index Terms: red pitaya fruit seed, extraction condition, antioxidant, DPPH radical scavenging activity, response surface methodology.

\section{INTRODUCTION}

Pitaya or dragon fruit belongs to a botanical family know as, Cactaceae with genus name of Hylocereus and is classified as a climbing plant with aerial roots [1]. Pitaya is in the shape of an oblong with scaly structure on its outer peel [2]. The flesh of the fruit is juicy and sweet with numerous small and grainy black seeds. Previous studies discovered the significant amount of polyunsaturated fatty acids (PUFA) particularly linoleic acid (C18:2) in pitaya seed oil. This essential fatty acid is reported to help relieve rough skin and keep the skin moisture [3]. As one of the grainy seeds rich in polyunsaturated fatty acid, pitaya seed is generally used to extract the oil in pharmaceutical and cosmetic industries. Nevertheless, the extraction residual which is the defatted

Revised Manuscript Received on September 22, 2019.

Siti Atikah Zulkifli, Halal Products Research Institute, Universiti Putra Malaysia, 43400 Serdang, Selangor, Malaysia.

Assoc. Prof. Madya Dr. Siti Salwa Abd Gani, Halal Products Research Institute \& Department of Agriculture Technology, Faculty of Agriculture, Universiti Putra Malaysia, 43400 Serdang, Selangor, Malaysia.

Dr. Uswatun Hasanah Zaidan, Department of Biochemistry, Faculty of Biotechnology and Biomolecular Sciences, Universiti Putra Malaysia, 43400 Serdang, Selangor, Malaysia.

Dr. Izuan Effendi Halmi, Department of Land Management, Faculty of Agriculture, Universiti Putra Malaysia, 43400 Serdang, Selangor, Malaysia. seed is often thrown away.

The exposure of biological system to air pollution, ionization radiation and smoking becomes the main source of free radical formation. Free radical formation such as reactive oxygen species (ROS) is very harmful and considered an unstable molecule that contributes to the beginning of biomolecules oxidation [4] which later on can lead to the cell damages such as cardiovascular disease, cataracts, and brain dysfunction [5]. Plant-based antioxidant is often reported as a radical scavengers that provides protection to the human body by inhibiting the oxidizing chain reactions [6].

Fruits and vegetables represent a major part in our diet due to their undoubted nutritional values for our health. Besides, they display a diverse range of pharmacological properties such as antioxidant capacity, antimicrobial, and anti-inflammatory activities [7]. This defensive action is generally assigned to the effects of the dietary fibers and the phenolic compounds. These compounds are bioactive substances commonly found in plants. Plant phenolic consists of a great diversity of compounds such as flavonoids (anthocyanins, flavanols, flavones) and several classes of non-flavonoids (phenolic acids, lignins, stilbenes) that contribute to the great antioxidant activity [8]. Therefore, the aim of this study has been focused toward exploring natural antioxidants from plant sources. Thus, defatted pitaya seed residual was utilized as experiment material to determine the antioxidant properties using response surface methodology (RSM).

RSM is a statistical method frequently used to optimize the process involving several parameters that can affect the response by determining the mutual interactions between the response values and independent variables. To the best of the authors' knowledge, there has not been a study reported on the antioxidant activity of defatted pitaya seed. Thus, the objective of the present study was to examine the antioxidant capacity of extracts, obtained under optimized conditions by the means of DPPH radical scavenging assay.

\section{MATERIALS AND METHOD}

\section{A. Materials and Reagent}

DPPH (1,1-diphenyl-2-picrylhydrazyl) and ethanol were purchased from Sigma Aldrich. Only analytical grade of chemicals was used throughout the experiment.

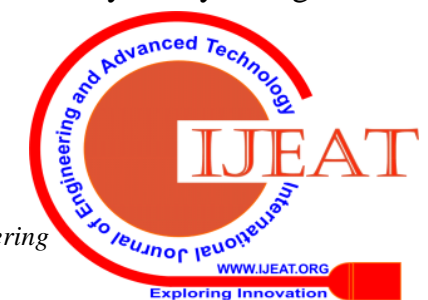


Fruits of red pitaya, H.polyrhizus, were collected from an orchard located in Sepang, Malaysia. For the pitaya seed preparation, the seeds were cleaned and washed under running water until all the flesh and pulp were removed. Seeds were then dried for $24 \mathrm{hrs}$ in an oven at $60^{\circ} \mathrm{C}$ and ground into smaller particles in a grinder. Then, the seeds were defatted by maceration method using n-hexane as the solvent. The defatted seeds were then left overnight in fume hood to let residual $n$-hexane evaporate before being used for antioxidants extraction.

\section{B. Extraction of Antioxidants Compounds}

$3 \mathrm{~g}$ of defatted seeds was mixed with ethanol of different concentrations in conical flask and placed in thermostatic water bath with constant shaking at $90 \mathrm{rpm}$. Parafilm and aluminum foils were used to cover the conical flask to prevent solvent loss during the extraction process. Then, the mixture was centrifuged at $10,000 \mathrm{rpm}$ at $25^{\circ} \mathrm{C}$ for $5 \mathrm{~min}$ to separate the insoluble material. The supernatant was filtered using the Whatman No. 1 filter paper and vacuum-dried in a rotary evaporator at $60{ }^{\circ} \mathrm{C}$ until the solvent was completely removed. All the samples were stored at $-20^{\circ} \mathrm{C}$ until further analysis.

\section{DPPH Radical Scavenging Activity}

The radical scavenging activity of each sample was carried out following a modified method described by [9]. Briefly, 10 $\mathrm{mg}$ of dried extract was weighed and dissolved in $10 \mathrm{~mL}$ ethanol $(1 \mathrm{mg} / \mathrm{ml}) .10 \mathrm{mg}$ of DPPH was dissolved in ethanol and made up to $100 \mathrm{~mL}$ in a volumetric flask $(0.1 \mathrm{mM})$. Then $50 \mu \mathrm{L}$ of the sample extracts was mixed with $150 \mu \mathrm{L}$ ethanolic solution of DPPH in 96-well plate microliter plate. The solution mixture was incubated in the dark at room temperature and the absorbance changes at $515 \mathrm{~nm}$ were measured 30 min later using a Microplate Reader (Spectra
Max Plus 384, Molecular Devices Co., Ltd., San Jose, CA, USA). The sample extract without DPPH was used as blank test. All the analyses were conducted in triplicate. The DPPH scavenging activities (DPPHsc) of the extracts were calculated using the following equation:

$\operatorname{DPPHsc}(\%)=((\mathrm{A} 0-\mathrm{A} 1) / \mathrm{A} 0) \times 100 \%$,

Where $A_{0}$ is the absorbance of the blank sample and $A_{1}$ is the absorbance of the sample.

\section{Experimental Design}

RSM was performed using Design Expert Software (Version 10.0.1, Stat-Ease, Inc Minneapolis, MN, USA) program. Five-level-factor, central composite design (CCD) was utilized to determine the optimized extraction condition for better antioxidant activity. The design comprised 20 experimental points, including six replications of the centre points. Three independent parameters were studied including extraction time (A), extraction temperature (B) and ethanol concentration $(\mathrm{C})$. Table I represents the coded and uncoded forms of five levels values of the experimental variables. The method of least squares regression was used by CCD to fit the data to a quadratic model. The quadratic model for each response is as follows:

$$
Y=\beta_{0}+\sum_{i=1}^{k} \beta_{i} X_{i}+\sum_{i=1}^{k} \beta_{i i} X_{i}^{2}+\sum_{i=1}^{k-1} \sum_{j=i+1}^{k} \beta_{i j} X_{i} X_{j}+e
$$

Where $\mathrm{Y}$ is the predicted response, $\beta_{0}$ a constant, $\beta_{\mathrm{i}}$ the linear coefficient, $\beta_{\mathrm{ii}}$ the quadratic coefficient, $\beta_{\mathrm{ij}}$ the interaction coefficient of variables $i$ and $j$, and $X_{i}$ and $X_{j}$ are independent variables. $\mathrm{k}$ is the number of variables and $\mathrm{e}$ is the error.

Table- I: Independent variables and their levels for CCD design

\begin{tabular}{ccccccc}
\hline Variable & & \multicolumn{5}{c}{ Coded \& uncoded level of variables } \\
\cline { 3 - 7 } s & Units & $-\alpha$ & -1 & 0 & 1 & $+\alpha$ \\
\hline A & Min & 9.55 & 30 & 60 & 90 & 110.46 \\
B & ${ }^{\circ} \mathrm{C}$ & 26.36 & 40 & 60 & 80 & 93.64 \\
$\mathrm{C}$ & $\%$ & 53.18 & 60 & 70 & 80 & 86.82 \\
\hline
\end{tabular}

\section{E. Verification of the Models}

The actual experimental values for optimal extraction conditions for DPPH in terms of independent variable (time, temperature and ethanol concentration) were determined by correlating with predicted value from the final response regression equations.

\section{RESULTS AND DISCUSSION}

\section{A. Model Fitting}

The experimental data for the response DPPH radical scavenging activity of red pitaya seed extracts are displayed in Table II. The result obtained showed that the DPPH radical scavenging activity of red pitaya seed extract ranged from $89.84-93.53 \%$. The least square method was used to calculate the regression coefficients of the intercept, linear, quadratic and interactive terms of the model [10] and revealed in Table III. It was revealed that two linear parameters, temperature (B) and ethanol concentration (C), interaction parameters, (BC) and quadratic parameters (B2) were significant at $(\mathrm{p}<0.05)$. The software generated the final predictive equation in terms of coded factors as shown in Equation 3, where empirical correlation between extraction time (A), temperature (B) and ethanol concentration $(\mathrm{C})$ was established. The analysis of variance (ANOVA) for the experimental results obtained in Table II discovered that the quadratic model was significant $(\mathrm{p}<$ $0.05)$ with no significance in the lack of fit $(p>0.05)$. The coefficient of determination (R2) acquired for this model was 0.9325 . This shows that 
only $6.75 \%$ of the total variations for DPPH radical scavenging activity could not be explained by the model.

$\mathrm{Y}_{(\mathrm{DPPH})}=+92.89-0.1639 \mathrm{~A}+0.5042 \mathrm{~B}+0.5095 \mathrm{C}-$ $0.1487 \mathrm{AB}+0.0963 \mathrm{AC}-0.7113 \mathrm{BC}-0.0777 \mathrm{~A}^{2}$

$$
-0.6982 B^{2}+0.0531 C^{2}
$$

\section{B. Optimum Extraction Condition based on DPPH}

The DPPH radical scavenging activity of pitaya seed extract ranged from $89.84-93.53 \%$. The mean recorded value was $92.40 \%$. The highest value was recorded for run No. 18 whereas the lowest value recorded was discovered at experiments No. 3. The recovery of DPPH radical scavenging activity was estimated based on the varied value of the tested factor using response surface. The three-dimensional response surface and two-dimensional contours designed by the fitted model are demonstrated in Figures 1-3. Each diagram shows the effects of mutual interaction between the extraction parameters on the yielded DPPH radical scavenging activity by holding the other variables at their zero level.

Fig. 1 illustrates the interactions between the extraction time and temperature on DPPH radical scavenging activity at concentration of the solvent which which fixed at $70 \%$. It was observed that the scavenging activity was increased as extraction.

Table- II: The experimental results of DPPH radical scavenging activity from red pitaya seed extract.

\begin{tabular}{|c|c|c|c|c|}
\hline $\begin{array}{l}\mathrm{Ru} \\
\mathrm{n}\end{array}$ & $\begin{array}{l}\text { Time } \\
\text { (A) }\end{array}$ & $\begin{array}{l}\text { Temperatur } \\
\text { e } \\
\text { (B) }\end{array}$ & $\begin{array}{l}\text { Ethanol } \\
\text { concentratio } \\
\mathrm{n}(\mathrm{C})\end{array}$ & $\begin{array}{l}\text { DPPH } \\
(\%)\end{array}$ \\
\hline 1 & $-\alpha$ & 0 & 0 & 92.97 \\
\hline 2 & 0 & 0 & 0 & 92.35 \\
\hline 3 & 0 & $-\alpha$ & 0 & 89.84 \\
\hline 4 & 1 & 1 & 1 & 92.28 \\
\hline 5 & $\alpha$ & 0 & 0 & 92.18 \\
\hline 6 & -1 & 1 & -1 & 92.98 \\
\hline 7 & -1 & -1 & -1 & 90.66 \\
\hline 8 & 1 & -1 & 1 & 93.4 \\
\hline 9 & 0 & 0 & 0 & 92.97 \\
\hline 10 & 0 & 0 & 0 & 93.1 \\
\hline 11 & 0 & 0 & $-\alpha$ & 92.36 \\
\hline 12 & 0 & 0 & 0 & 93.36 \\
\hline 13 & 0 & $\alpha$ & 0 & 91.8 \\
\hline 14 & 0 & 0 & 0 & 92.51 \\
\hline 15 & -1 & 1 & 1 & 92.91 \\
\hline 16 & 1 & -1 & -1 & 90.24 \\
\hline 17 & 0 & 0 & 0 & 93.08 \\
\hline 18 & 0 & 0 & A & 93.53 \\
\hline 19 & -1 & -1 & 1 & 92.84 \\
\hline 20 & 1 & 1 & -1 & 92.56 \\
\hline
\end{tabular}

temperature ascended over time. The results marked that an increase in temperature led to an increase in antioxidant

activity. This phenomenon was probably because of higher temperature can improve the mass transfer as well as increase the extracted molecules. However, immoderate increase of temperature during the extraction process may

(3) affect the stability of the phenolic compounds due to chemical and thermal degradations of some phenolic compounds accounting for decreased antioxidant activity which were previously mobilized at low temperature [11]. This was supported by the outcome obtained showing the scavenging activity was decreased after the temperature was elevated from $70{ }^{\circ} \mathrm{C}$ to $80^{\circ} \mathrm{C}$. This similar type of occurrence was also revealed by [12] that the antioxidant capacity of $C$. asiatica extract was stable up to $50{ }^{\circ} \mathrm{C}$. Thus, it is believed that the polyphenol compounds extracted under high temperature had lower antioxidant activity as compared to those extracted under moderate temperature.

Extraction time is an important factor to be considered in minimizing energy and cost of the extraction procedure. The extraction time can either be as short as few minutes or very long as up to 24 hours [13], [14]. The influence of interactive effect between extraction time and ethanol concentration on DPPH radical scavenging activity is exhibited in Fig. 2. The highest antioxidant activity observed extraction time increased from 30 - 70 min was accompanied by small increment in antioxidant capacity. Prolonging the process duration up to $90 \mathrm{~min}$ did not significantly improve the radical scavenging activity. This occurrence could be explained by Fick's second law of diffusion, which states that a final equilibrium will be accomplished between the concentration of the solute in the solid matrix (plant matrix) and in bulk solution (solvent) after a certain time [15]. Moreover, continuing the extraction period might induce the risk of phenolic oxidation unless reducing agents are added to the solvent system [16].

Table- III: Analysis of variance (ANOVA)

\begin{tabular}{lllll}
\hline Source & $\begin{array}{l}\text { Sum of } \\
\text { Squares }\end{array}$ & $\begin{array}{l}\text { Mean } \\
\text { Square }\end{array}$ & F-value & p-value \\
\hline Model & 18.93 & 2.1 & 15.35 & $<0.0001$ \\
A & 0.38 & 0.38 & 2.68 & 0.1328 \\
B & 3.47 & 3.47 & 25.33 & 0.0005 \\
C & 3.54 & 3.54 & 25.86 & 0.0005 \\
$\mathrm{AB}$ & 0.18 & 0.18 & 1.29 & 0.2823 \\
$\mathrm{AC}$ & 0.07 & 0.07 & 0.54 & 0.479 \\
$\mathrm{BC}$ & 4.05 & 4.05 & 29.53 & 0.0003 \\
$\mathrm{~A}^{2}$ & 0.09 & 0.08 & 0.64 & 0.444 \\
$\mathrm{~B}^{2}$ & 7.03 & 7.03 & 51.26 & $<0.0001$ \\
$\mathrm{C}^{2}$ & 0.04 & 0.04 & 0.3 & 0.5981 \\
Residual & 1.37 & 0.14 & & \\
Lack of Fit & 0.63 & 0.13 & 0.8439 & 0.5716 \\
Pure Error & 0.7434 & 0.15 & & \\
Cor Total & 20.3 & & & \\
Std. Dev & 0.3702 & $\mathrm{R}^{2}$ & 0.9325 & \\
Mean & 92.4 & Adj. $\mathrm{R}^{2}$ & 0.8717 & \\
C.V \% & 0.4007 & & & \\
\hline
\end{tabular}


Meanwhile, the effects of temperature versus ethanol concentration at constant extraction time $60 \mathrm{~min}$ revealed that DPPH radical scavenging activity increased with the increase of the ethanol concentration as displayed in Fig. 3.

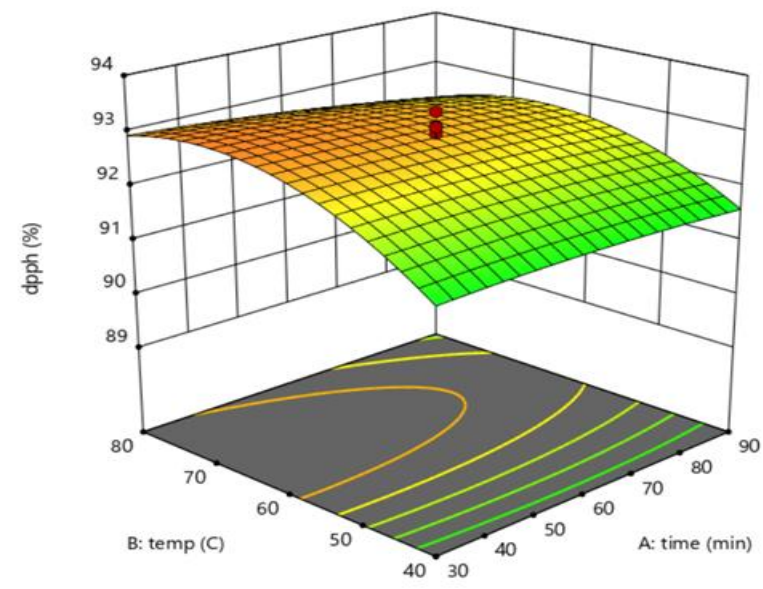

Fig. 1. Interactive effect of extraction time and temperature on DPPH radical scavenging activity

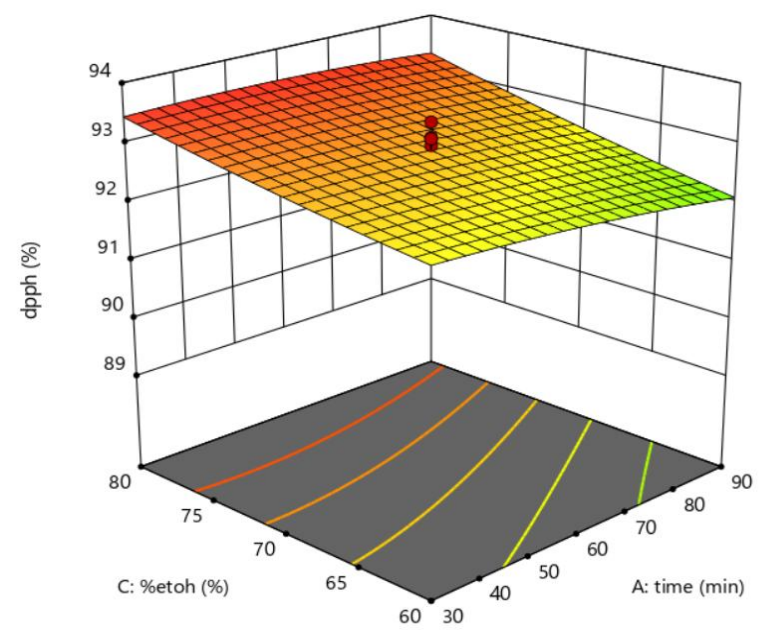

Fig. 2. Interactive effect of extraction time and ethanol concentration on DPPH radical scavenging activity

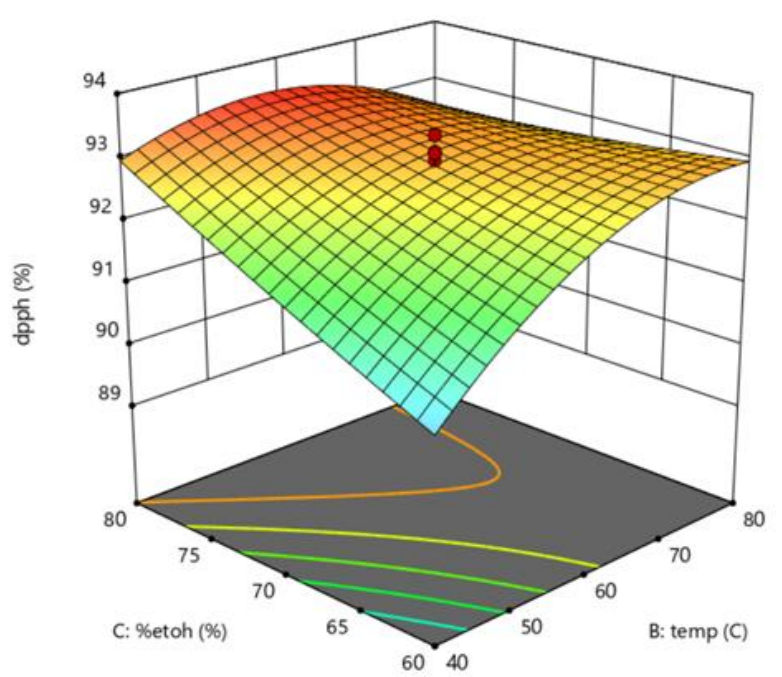

Fig. 3. Interactive effect of temperature and ethanol concentration on DPPH radical scavenging activity

Previous studies reported that binary-solvent system demonstrated higher yield of polyphenol compounds as compared to mono-solvent system [17]-[20]. This is because water is reported to act as a plant swelling agent, while ethanol can disrupt the bonding between the solutes and plants matrices [21] which therefore more phenolic compound accountable for antioxidant activity can be extracted.

\section{Verification of the Models}

The numerical optimization of extraction parameters for better DPPH radical scavenging activity was determined using Design Expert (version 10.0.1, Stat-Ease, Inc). The experiment was performed referring to the recommended optimum treatment conditions which were 45 mins of extraction time, $70^{\circ} \mathrm{C}$ extraction temperature and $80 \%$ ethanol concentration.

The adequacy of the response surface models for predicting the optimum response value was verified by comparing the experimental and predicted value of response (Table IV). The obtained results from verification experiment were in close agreement with predicted value where deviation between the experimental and predicted values found to be insignificant ( $p>0.05)$.

Table- IV: Response values under optimal conditions at 45 minutes of extraction time, $70^{\circ} \mathrm{C}$ extraction temperature and $80 \%$ ethanol concentration.

\begin{tabular}{llll}
\hline Response & Predicted & Experimental \\
\hline $\begin{array}{l}\text { DPPH radical } \\
\text { activity }(\%)\end{array}$ & scavenging & 93.23 & $92.56 \pm 0.21$ \\
\hline
\end{tabular}

\section{CONCLUSION}

Response surface methodology was successfully employed in this study for optimization of extraction procedure that gives maximum DPPH radical scavenging activity. The result revealed that extraction temperature and ethanol concentration significantly influenced the measured response. The optimized condition identified was at $45 \mathrm{mins}$ of extraction time, $70^{\circ} \mathrm{C}$ extraction temperature and $80 \%$ ethanol concentration that ensure better recovery of response at $92.89 \%$. The results indicated that red pitaya seeds extract has a good antioxidant activity. Moreover, further studies should be conducted for the recovery of polyphenolic compounds before a large-scale production of red pitaya seed extract can be suggested. 


\section{REFERENCES}

1. J. C. Choo, R. Y. Koh, and A. P. K. Ling, "Medicinal properties of Pitaya: A review," ScopeMed, vol. 6, no. 2, Apr. 2016, pp. 69-76.

2. S. R. Nurul, and R. Asmah, "Variability in nutritional composition and phytochemicals properties of red pitaya (Hylocereus polyrhizus) from Malaysia and Australia," Int Food Res J., vol. 21, no. 4, March. 2014, pp. 1689-1697.

3. A. A. Ariffin, J. Bakar, C. P. Tan, R. Abdul Rahman, R. Karim, and C. C. Loi, "Essential fatty acids of pitaya (dragon fruit) seed oil," Food Chem, vol. 114, May. 2009, pp. 561-564.

4. S. Kumar, D. Kumar, Manjusha, K. Saroha, N. Singh, and B. Vashishta "Antioxidant and free radical scavenging potential of Citrullus colocynthis (L.) Schrad. methanolic fruit extract," Acta Pharm, vol. 58, no. 2, April 2008, pp. 215-20.

5. C.K. Ashok Kumar, M. Tejasri, D. Satheesh Kumar, M. Ramya, K. Revathi, and G. A. K. Reddy, "A Review on antioxidants," Int. J Innovative Drug Discovery, vol. 2, no. 2, 2012, pp. 98-114.

6. A. S. Ribeiro, M. Estanqueiro, M. B. Oliveira, and J. M. S. Lobo, "Main Benefits and Applicability of Plant Extracts in Skin Care Products," Cosmetics, vol. 2, Apr. 2015, pp. 48-65.

7. J. Deng, Q. Liu, C. Zhang, W. Cao, D. Fan, and H. Yang, "Extraction Optimization of Polyphenols from Waste Kiwi Fruit Seeds (Actinidia chinensis Planch.) and Evaluation of Its Antioxidant and Anti-Inflammatory Properties," Molecules, vol. 21, no. 832, June. 2016 pp. 2-13.

8. M. Kornsteiner, K. Wagner, and I. Elmadfa, "Tocopherols and tota phenolics in 10 different nut types," Food Chem, vol. 98, no. 2, 2006, pp 381-387.

9. M. S. Blois. "Antioxidant determinations by the use of a stable free radical," Nature, vol. 181, Apr. 1958, pp. 1199-1200.

10. G. Zhang, M. Hu, L. He, P. Fu, L. Wang, and J. Zhou, "Optimization of microwave-assisted enzymatic extraction of polyphenols from waste peanut shells and evaluation of its antioxidant and antibacterial activities in vitro," Food and Bioprod Processing, vol. 91, no. 2, Apr. 2013, pp 158-168.

11. M. Naczk, and F, Shahidi, "Extraction and analysis of phenolics in food," $J$ Chormatogr A 1054, vol. 1, no. 2, Oct. 2004, pp. 95-111.

12. A. Abdul Hamid, Z. Md. Shah, R. Muse, and S. Mohamed, "Characterisation of antioxidative activities of various extracts of Centella asiatica (L) Urban,” Food Chem, vol. 77, no. 4, June. 2002, pp. 465-569.

13. B. Lapornik, M. Prosek, and A. G. Wondra, "Comparison of extracts prepared from plant by-products using different solvents and extraction time," J Food Eng, vol. 71, Nov. 2005, pp. 214-222.

14. B. Lee, K. Jung, and Y. H. Choi, "Optimization of microwave-assisted extraction process of Rehmannia Radix preparata by response surface methodology," Food Engineering Progress, vol. 9, no. 4, 2005, pp. 283-290.

15. E. M. Silva, H. Rogez, and Y. Larondelle, "Optimization of extraction of phenolics from Inga edulis leaves using response surface methodology," Sep Purif Technol, vol. 55, July. 2007, pp. 381-387.

16. U. A. Fischer, R. Carle, and D. R. Kammerer, "Thermal stability of anthocyanins and colourless phenolics in pomegranate (Punica granatum L.) juices and model solutons," Food Chem, vol. 138, June. 2013 pp, 1800-1809.

17. R. Chirinos, H. Rogez, D. Campos, R. Pedreschi, and Y. Larondelle, "Optimization of extraction conditions of antioxidant phenolic compounds from mashua (Tropaeolum tuberosum Ruíz and Pavón) tubers," Sep Purif Technol, vol. 55, no. 2, June. 2007, pp. 217-225.

18. K. K. Chew, M. Z. Khoo, S. Y. Ng, Y. Y. Thoo, W. M. W. Aida, and C. W. Ho, "Effect of ethanol concentration, extraction time and extraction temperature on the recovery of phenolic compounds and antioxidant capacity of Orthosiphon stamineus extracts," Int. Food Res. J., vol 18 2011, pp. 1427-1435.

19. G. Spigno, L. Tramelli, and D. M. D. Faveri, "Effects of extraction time, temperature and solvent on concentration and antioxidant activity of grape marc phenolics," J Food Eng, vol. 81 no. 1, July. 2007, pp. 200- 208.

20. J. Wang, B. Sun, Y. Cao, Y. Tian, and X. Li, "Optimisation of ultrasound-assisted extraction of phenolic compounds from wheat bran," Food Chem, vol. 106, no. 2, Jan. 2008, pp. 804-810.

21. S. Sahin, and R. Samli, "Optimization of olive leaf extract obtained by ultrasound-assisted extraction with response surface methodology," Ultrason Sonochem, vol. 20, Jan. 2013, pp. 595-602.

\section{AUTHORS PROFILE}

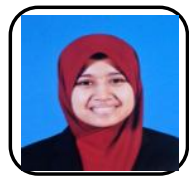

Siti Atikah Zulkifli, Master of Science, 2017, Halal Product Development, Halal Products Research Institute, Universiti Putra Malaysia, 43400 Serdang, Selangor, Malaysia.

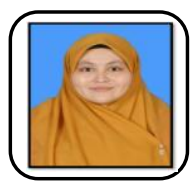

Siti Salwa Abd Gani Doctor of Philosophy, 2010, Agriculture Product Development, Oleochemistry and Formulation Science, Universiti Putra Malaysia, 43400 Serdang, Selangor, Malaysia.

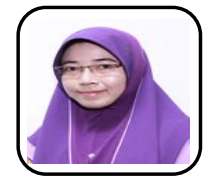

Uswatun Hasanah Zaidan, Doctor of Philosophy, Food Biochemistry, Universiti Putra Malaysia, 43400 Serdang, Selangor, Malaysia.

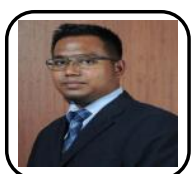

Mohd Izuan Effendi Halmi, Doctor of Philosophy, 2015, Environmental Biochemistry, Ecotoxicology and Bioluminescence, Universiti Putra Malaysia, 43400, Serdang, Selangor, Malaysia. 